\title{
Adaptations of lateral hand movements to early and late visual occlusion in catching
}

\author{
Joost C. Dessing $\cdot$ Leonie Oostwoud Wijdenes • \\ C. (Lieke) E. Peper $\cdot$ Peter J. Beek
}

Received: 8 February 2008/Accepted: 16 September 2008/Published online: 21 October 2008

(C) The Author(s) 2008. This article is published with open access at Springerlink.com

\begin{abstract}
Recent studies suggested that the control of hand movements in catching involves continuous visionbased adjustments. More insight into these adjustments may be gained by examining the effects of occluding different parts of the ball trajectory. Here, we examined the effects of such occlusion on lateral hand movements when catching balls approaching from different directions, with the occlusion conditions presented in blocks or in randomized order. The analyses showed that late occlusion only had an effect during the blocked presentation, and early occlusion only during the randomized presentation. During the randomized presentation movement biases were more leftward if the preceding trial was an early occlusion trial. The effect of early occlusion during the randomized presentation suggests that the observed leftward movement bias relates to the rightward visual acceleration inherent to the ball trajectories used, while its absence during the blocked presentation seems to reflect trial-by-trial adaptations in the visuomotor gain, reminiscent of dynamic gain control in the smooth pursuit system. The movement biases during the late occlusion block were interpreted in terms of an incomplete motion extrapolation - a reduction of the velocity gaincaused by the fact that participants never saw the to-beextrapolated part of the ball trajectory. These results underscore that continuous movement adjustments for
\end{abstract}

J. C. Dessing - L. Oostwoud Wijdenes · C. E. Peper · P. J. Beek Research Institute MOVE, Faculty of Human Movement Sciences, VU University Amsterdam, Amsterdam,

The Netherlands

J. C. Dessing ( $₫)$

Faculty of Human Movement Sciences,

VU University Amsterdam, Van der Boechorststraat 9,

1081 BT Amsterdam, The Netherlands

e-mail: joost.dessing@fbw.vu.nl catching do not only depend on visual information, but also on visuomotor adaptations based on non-visual information.

Keywords Interception - Vision - Target velocity · Visuomotor control $\cdot$ Arm movements

\section{Introduction}

Accurate reaching and grasping are essential for many object manipulation tasks and this accuracy often depends on the adequate use of visual information about object properties (such as the location and orientation of a to-begrasped cup of coffee). These properties must be coded in neural activity of relevant brain areas (Batista et al. 1999; Buneo et al. 2002) and transformed into the muscle activation patterns generating the appropriate muscle forces for accurate reaching (Gribble and Ostry 1998; Kistemaker et al. 2006). With respect to this visuomotor transformation, interceptive reaching is particularly interesting, because it requires vision-based movement updates.

While only few studies have directly addressed the neural basis of visuomotor transformations for interception (Ilg and Schumann 2007; Lee et al. 2001; Merchant et al. 2004; Port et al. 2001; Schenk et al. 2005), a vast number of behavioral studies on interception have been performed. A large part of these studies focused on the predictive control of movement timing (Bootsma and van Wieringen 1990; Fitch and Turvey 1978; Lee et al. 1983; McLeod 1987; Savelsbergh et al. 1991; Tyldesley and Whiting 1975), while others focused more on the vision-based movement adjustments used to reach the right place at the right time (Brenner et al. 1998; Dessing et al. 2005; Jacobs and Michaels 2006; Montagne et al. 1999; Peper et al. 1994; Smeets and Brenner 1995). The present study 
extends the latter line of research by examining the effects of predictable and unpredictable occlusion on vision-based movement adjustments underlying catching.

Occlusion has been used extensively in interception studies that focused on motion extrapolation (Brouwer et al. 2002, 2003; Eggert et al. 2005; Lacquaniti and Maioli 1987, 1989; Mrotek and Soechting 2007a; Teixeira et al. 2006). In the early 1970s, Whiting et al. showed that balls can be caught successfully when their trajectories are largely occluded (Whiting et al. 1970; Sharp and Whiting 1974), but they did not examine the corresponding hand movements. Whereas Mazyn et al. (2007) examined hand movements as a function of the effects of approach velocity and occlusion, they did not vary the lateral ball motion, which has been shown to affect vision-based movement adjustments in catching (Dessing et al. 2005; Peper et al. 1994; see also Montagne et al. 1999). Combined variations of lateral ball motion and occlusion may therefore be expected to yield interesting new insights in this respect.

We used pendular ball trajectories passing at various lateral distances from the participant's head on his or her right hand side (Fig. 1a), approaching the passing position from the left and the right (i.e., from different directions). Participants caught the ball with their right hand. Hand movements in this set-up are consistently biased leftward (Dessing et al. 2005). This was particularly evident when the hand started at the ball's future passing position (unbeknownst to the participant): in this situation the hand was first moved leftward (i.e., away from the starting position), after which movement direction was reversed to catch the ball at the starting position. An explanation of this leftward bias was found in the corresponding visual ball motion, in that the ball visually starts to the left of the hand (irrespective of its physical approach direction) and continuously accelerates rightward (Fig. 1). Visually, the ball moves largely downward initially, while its lateral motion becomes stronger later in the trajectory. The observed leftward movement bias may be understood from this pattern, because movement adjustments in interception mainly depend on visual position and velocity information (Brouwer et al. 2002, 2003, 2005; Dessing et al. 2005; Montagne et al. 1999). In essence, this implies that the ball's future rightward visual displacement is underestimated because visual acceleration is not (fully) taken into account (see also Werkhoven et al. 1992). This underestimation should be smaller if less time remains (i.e., closer to contact) because the rightward visual ball velocity keeps increasing. This predicts that later movement initiation should yield a smaller leftward movement bias. We examined this prediction by occluding ball motion early in its trajectory, which was expected to delay movement initiation because the ball becomes visible later.

We also included a condition in which ball motion was occluded in the last part of its trajectory, to follow up on
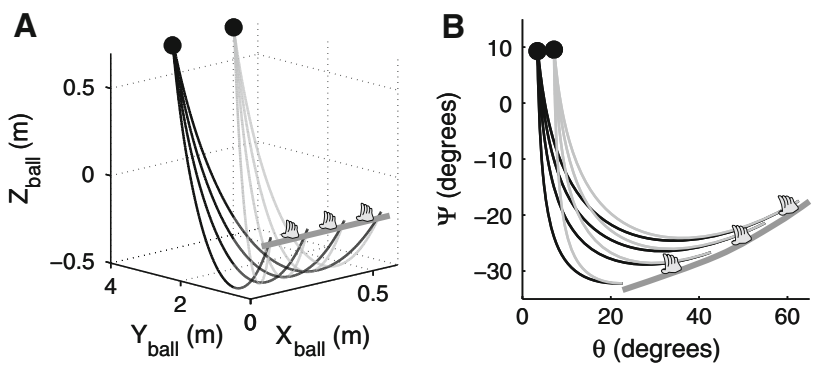

Fig. 1 a The $x$-, $y$-, and $z$-coordinates of the balls ( $X_{\text {ball }}, Y_{\text {ball }}$, and $Z_{\text {ball }}$, respectively; note the difference in scale between the dimensions), with the observation point located at coordinate $(0,0,0)$. b The lateral $(\theta)$ and vertical $(\psi)$ visual coordinates (Fick angles) calculated for the ball trajectories presented in a. In both panels, the initial visual ball positions are indicated by black circles and the initial hand positions used in the experiments are depicted on top of a gray line representing the bar that constrained the movements to the lateral direction

the aforementioned work of Whiting and Mazyn. To 'force' our participants to extrapolate ball motion we used an occlusion window of $400 \mathrm{~ms}$, which is considerably longer than typical estimates of the visuomotor delay (100$200 \mathrm{~ms}$, Brenner et al. 1998; Saunders and Knill 2005). Due to the predominance of visual position and velocity information in motion extrapolation (Bennett and Barnes 2003; Brouwer et al. 2002, 2003, 2005; Churchland et al. 2003), ball motion during the occlusion may be expected to be underestimated, resulting in a leftward movement bias at interception (see explanation above). However, given that our participants will try to catch the ball, they might adapt the extrapolation process. Mrotek and Soechting (2007a) for instance showed that curvilinear target motion can be accurately extrapolated only if visual feedback of the post-occlusion path is provided, while de Lussanet et al. $(2001,2002)$ showed effects of target velocity in previous trials on the spatial features of hitting movements (see also Krauzlis and Adler 2001; Stocker and Simoncelli 2006). To anticipate, evidence for such adaptations during the blocked presentation of the occlusion conditions was indeed found. We therefore ran a second control experiment in which the occlusion conditions were presented in random order (see van Donkelaar et al. 1992 and Song and Nakayama 2007 for similar comparisons of blocked vs. randomized presentations).

\section{Method}

Participants

Fourteen right-handed (mean laterality quotient of 96.6, Oldfield 1971) healthy adults participated in "Experiment 1". For two participants the experiment was terminated prematurely, for one as a consequence of technical failure 
and for the other due to inadequate performance. These participants were excluded from the analyses, yielding a remaining total of 12 participants (six males, six females, mean age 24.5 years, range 19-52), who also participated in "Experiment 2". They reported normal or corrected-tonormal vision (stereo acuity $<40$ arcs; Stereo Fly Test, Stereo Optical Co., Inc., Chicago, IL) and gave their informed consent before participating in either experiment.

\section{Experimental set-up}

The experimental set-up was largely the same as that used by Dessing et al. (2005). Participants sat in a chair, while catching balls approaching from the front and passing them on the right (Fig. 2a; see also Fig. 1a). Their right hand could be moved in the lateral direction only, along a horizontal bar positioned just below shoulder level (i.e., $1.07 \mathrm{~m}$ above the ground). Balls (diameter $8 \mathrm{~cm}$; mass $0.145 \mathrm{~kg}$ ) approached the participants along one of eight trajectories that were defined by two initial ball positions (IBPs $25 \mathrm{~cm}$ apart; referred to as $\mathrm{IBP}_{\text {near }}$ and $\mathrm{IBP}_{\text {far }} ; \mathrm{IBP}_{\text {near }}$ was located $32.5 \mathrm{~cm}$ to the right of the center of the chair; the initial angle of the pendulum, relative to equilibrium, was $59.5^{\circ}$ ) and four interception points (IPs, $15 \mathrm{~cm}$ apart; referred to as IP1, IP2, IP3, and IP4, respectively; IP1 was located $22.5 \mathrm{~cm}$ to the right of the center of the chair) (Fig. 2a). The position of the bar was adjusted such that the balls could be caught $7.5 \mathrm{~cm}$ in front of and $7.0 \mathrm{~cm}$ above it, because pilot measurements had shown that this was the average position of the center of the ball relative to the bar when it was held stationary at the lateral distance of the IPs. The hand started at one of three initial hand positions (IHPs, $15 \mathrm{~cm}$ apart, located in between the IPs; referred to as $\mathrm{IHP}_{\text {near }}, \mathrm{IHP}_{\text {middle, and }} \mathrm{IHP}_{\text {far }}$; see Fig. 2a). Balls were suspended from the ceiling (at a height of $3.30 \mathrm{~m}$ ) using plastic coated steel wires (length $2.50 \mathrm{~m}$, diameter $0.2 \mathrm{~mm}$ ) with a little magnet at the lower end. Five different wires were used, which were hanging $9.4 \mathrm{~cm}$ apart in lateral direction so that each ball's pendular movement would pass the designated IP (Fig. 2a). During each trial, the unused wires were connected with the little magnet to a metal bar $20 \mathrm{~cm}$ above the IBPs. A screw was embedded in the balls and a metal plate was attached to the ball using a short Kevlar wire (see Fig. 2b). Prior to release, the coated steel wire was attached to the screw in the ball and the ball was pulled up and back to one of the IBPs $(2.04 \mathrm{~m}$ high, $3.5 \mathrm{~m}$ in front of the IPs) and connected via the metal plate to an electromagnet (see Fig. 2b). When participants caught the ball the magnet usually detached from the ball due to the impact. Glow-in-the-dark balls were used and these were charged by two UV-emitting fluorescent tubes, suspended about $15 \mathrm{~cm}$ below the IBPs. Besides these tubes, the balls and control computer were the only light sources present during the experiment; light from the control computer was prevented from reaching the participant using a screen. Participants could just see their hand when specifically asked to look at it, but they reported not seeing it during the actual trials.

An Optotrak camera system (model 3020, Northern Digital, Inc., Waterloo, Canada), which was positioned $2.2 \mathrm{~m}$ on the right of the participant at a height of approximately $2 \mathrm{~m}$, registered the position (at $250 \mathrm{~Hz}$ ) of an infrared emitting diode placed on a piece of Polystyrene taped to the back of the hand. In addition, a cluster marker pointing in a different direction than the diode was placed on the Polystyrene, to be used for reconstruction of the diode position if necessary (see "Data reduction"). The Optotrak recordings were triggered at the moment of ball release.

Vision was controlled by switching liquid crystal glasses (PLATO system, model P-1, Translucent Technologies, Toronto, Canada) from opaque to transparent and vice versa. In the no-occlusion condition balls became visible at ball release and invisible after $1,158 \mathrm{~ms}$, which was on average $24 \mathrm{~ms}$ before the ball reached the IP [flight times were measured after the experiment (accuracy $2 \mathrm{~ms}$ ) using an Optotrak camera placed perpendicular to the lateral axis through the IPs, using the occlusion time of a marker placed just behind the ball's passing position]. In the late occlusion condition balls became visible at ball release and invisible after $758 \mathrm{~ms}$, while in the early occlusion condition balls became visible $398 \mathrm{~ms}$ after ball release and invisible at $1,158 \mathrm{~ms}$ after ball release.

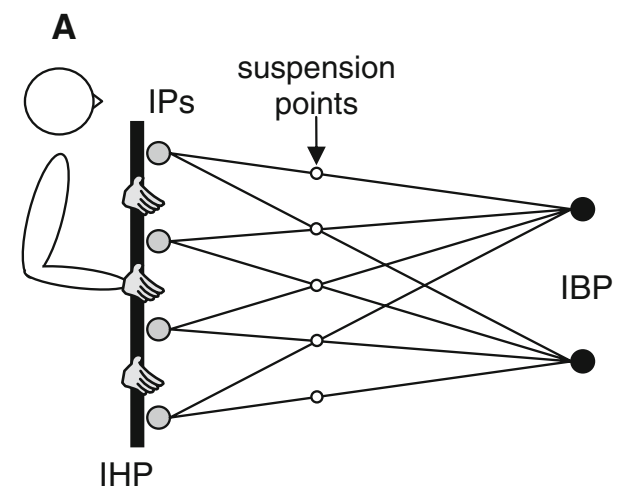

B

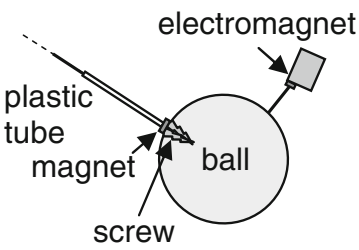

Fig. 2 a Top-view of the configuration of the initial ball position $(I B P s)$, suspension points, interception points (IPs), and initial hand positions (IHPs). Note that each ball moved in a plane represented by the line. b Illustration of the suspension mechanism of the balls 


\section{Procedure}

Participants were instructed to catch the approaching ball with their right hand and were free to also move their head and body. They were informed when the next trial was going to start, and balls were released 500-1,500 ms (randomized) after the experimenter pressed a key. When the trial ended, participants were free to move their hand to a comfortable position. The experimenter manually guided the participant's hand from this self-selected hand position to the IHP for the new trial (where the hand was held open, upright, with the palm facing forward). The ball was then attached to the wire and suspended at the IBP of the next trial (in this period, the liquid crystal glasses were opaque, preventing prior knowledge of the upcoming ball trajectory). If a ball was not caught, the experimenter marked the trial number on the experimental log. Two experiments of 144 trials (two repetitions of all combinations of three occlusion conditions, two IBPs, four IPs, and three IHPs) were run on separate days (about nine months apart). In "Experiment 1" the occlusion conditions were presented in three separate blocks (i.e., one per condition, with the order of presentation being counterbalanced over the participants), separated by a 5-min break, within which all trials were presented in random order. In "Experiment 2" all conditions (including the occlusion conditions) were presented in random order, with the two repetitions being presented in two separate blocks (separated by a $5 \mathrm{~min}$ break). Before each experiment, participants were given 4-8 practice trials in the no occlusion condition. Running the experiments took about $90 \mathrm{~min}$ each. After "Experiment 1" we asked the participants to judge the number of IBPs, IPs, and IHPs used in the experiment. All procedures were approved by the ethics committee of the Faculty of Human Movement Sciences of VU University Amsterdam before the experiment was conducted.

\section{Data reduction}

Both successful (i.e., trials in which the ball was caught; $n=3,063)$ and unsuccessful trials $(n=393)$ were included in the analyses. In 88 trials the position of the hand marker was missing for more than 25 consecutive samples and was therefore reconstructed from the cluster marker. For all other trials with missing values the hand marker position was reconstructed using a cubic spline interpolation. The position signals were low-pass filtered using a bidirectional (zero-lag) fourth order Butterworth filter (cutoff frequency $10 \mathrm{~Hz}$ ). In total 44 trials were excluded, because the movements could not be reconstructed from the cluster marker, or because the data showed that the hand had not been positioned correctly initially or that the ball was attached to the wrong wire by the experimenters (for all conditions in both experiments at least one correct trial was retained).

The lateral position of the hand marker was used to calculate three previously used dependent variables (Dessing et al. 2005) that together adequately captured the essential features of the hand movements, viz., the moment of movement initiation $\left(T_{\mathrm{ini}}\right)$, the hand trajectory bias $\left(\Delta X_{\mathrm{h}-\mathrm{av}}\right)$, and the constant error of the hand position at interception $\left(\mathrm{CE}_{\mathrm{HPI}}\right)$. $T_{\mathrm{ini}}$ was used to examine the prediction that early occlusion results in later initiation (late occlusion was expected not to affect $T_{\text {ini }}$ ). It was defined as the moment at which the absolute lateral hand velocity exceeded $2 \%$ of the first velocity peak that was larger than $5 \mathrm{~cm} \mathrm{~s}^{-1} . T_{\text {ini }}$ was defined positive and expressed relative to the moment the ball passed the IP [i.e., a smaller (larger) $T_{\text {ini }}$ signals a later (earlier) movement initiation]. $\Delta X_{\mathrm{h}-\mathrm{av}}$ was examined to test the expectation that early occlusion yields a smaller leftward movement bias. It was defined as the average lateral hand position from initiation to interception relative to a position exactly in between the IHP and IP. $\mathrm{CE}_{\mathrm{HPI}}$ was used to examine the accuracy of the hand positioning at the moment of interception (this measure was particularly interesting when motion extrapolation was required, i.e., for late occlusion). $\mathrm{CE}_{\mathrm{HPI}}$ was defined as the lateral hand position at interception relative to the IP (i.e., $\mathrm{CE}_{\mathrm{HPI}}>0$ indicates a hand position to the right of the IP). We included a fourth dependent variable, because close inspection of the hand trajectories in the blocked design suggested that the hand movements may have been biased leftward for late occlusion compared to no occlusion, possibly even before the onset of the occlusion. To examine this suggestion, we calculated the early movement bias $\left(\Delta X_{\mathrm{h} \text {-early }}\right)$, which we defined as the hand position at $758 \mathrm{~ms}$ after ball release (i.e., the moment the occlusion started in late occlusion trials), expressed relative to the position of a minimal jerk trajectory (Flash and Hogan 1985) from the hand position at initiation to the IP at that moment (with a movement time equaling $T_{\text {ini }}$ ). The latter procedure was included to minimize the effects of variations in movement time and movement distance on $\Delta X_{\mathrm{h}-\text { early }}$.

\section{Statistical analyses}

Success rates in the three occlusion conditions were analyzed using a Friedman analysis of variance (ANOVA $P<0.05$ ), with Wilcoxon signed rank post hoc tests (Sidak step-down-adjusted $P$ values). Although the two occlusion windows were selected to test separate hypotheses, we analyzed their effects in a single repeated measures ANOVA $(P<0.05)$ for the sake of completeness. For both experiments, the ANOVAs included the factors Occlusion (three levels no, late, and early occlusion), IBP (two levels 
$\mathrm{IBP}_{\text {near }}$ and $\mathrm{IBP}_{\text {far }}$ ), IHP (three levels $\mathrm{IHP}_{\text {near }}$, IHP $\mathrm{IHiddle}_{\text {, }}$ and $\mathrm{IHP}_{\text {far }}$ ), and IP (four levels IP1, IP2, IP3, and IP4). When the assumption of sphericity was violated (as indicated by a significant Mauchly test) the Huynh-Feldt corrected degrees of freedom were used (and reported in the "Results"). Paired-samples $t$ tests were used for post hoc analyses, with Sidak step-down-adjusted $P$ values for each test of main effects (i.e., for an $A \times B$ interaction, separate adjustments were made for tests of effects of $A$ and tests of effects of $B$ ). For $\Delta X_{\mathrm{h} \text {-early }}$ the factor Occlusion only had two levels (no and late occlusion; the comparison with early occlusion in this case made no sense, given the expected and observed later initiation in this condition). Data are presented as "mean \pm SD", and reported in the order of the levels as mentioned in this paragraph, unless stated otherwise.

Since "Experiment 2" was a control experiment, we will only discuss the effects and interactions involving the factor Occlusion (i.e., nearly all other effects were similar in both experiments). Moreover, to examine the influence of the preceding occlusion condition in the randomized design, additional ANOVAs were performed on the single trial values of all dependent variables in which the onset time of vision ( 0 or $398 \mathrm{~ms}$ ) and offset time of vision (758 or $1,158 \mathrm{~ms}$ ) were taken as covariates (repeated measures implemented by including a factor Participant with 12 levels).

\section{Results}

Experiment 1: blocked Occlusion conditions

As in our related previous experiments (Dessing et al. 2004, 2005), most participants were not aware of the number of IBPs, IPs, and IHPs used, overestimating these numbers by two or three. This reassured us that the control of hand movements predominantly depended on online vision rather than on visual memory of the ball trajectories. Success rates differed significantly between the Occlusion conditions $\left[\chi^{2}(2,12)=20.35, P<0.001\right]$ and the post hoc analyses showed that catching success increased from late occlusion $(75.8 \%)$ to early occlusion $(91.8 \%)$ to no occlusion $(95.7 \%)$ (all differences significant). In the following, we discuss the effects of our experimental manipulations on lateral hand movements. Table 1 contains the $F$ values and $\eta_{\mathrm{p}}^{2}$ s for all significant main effects of all dependent variables in "Experiment 1", as well as the average values of the different levels. To illustrate these main effects and the interaction effects, the hand trajectories averaged over all participants ( \pm SE for each sample) for all conditions are shown in Fig. 3.
Moment of initiation $\left(T_{\text {ini }}\right)$

Post hoc analyses of the effect of Occlusion on $T_{\text {ini }}$ showed that catching movements were initiated significantly later when the first part of the ball flight was occluded, compared to no and late occlusion. Post hoc analyses of the effect of IP revealed a significantly earlier initiation for balls passing at IP1 than for balls passing at IP2. The effect of IHP for $T_{\text {ini }}$ indicated that catching movements were initiated earlier the further the hand started to the right (all differences significant). The Occlusion $\times$ IHP interaction $\left[F(3.6,39.2)=2.89, P<0.05, \eta_{\mathrm{p}}^{2}=0.21\right]$ revealed that the effect of IHP was significant in the no occlusion block $\left(T_{\text {ini }}\right.$ S of $652 \pm 106,685 \pm 90$, and $725 \pm 98$ ms; significant difference between $\mathrm{IHP}_{\text {far }}$ and $\mathrm{IHP}_{\text {near }}$ ), but not in the late occlusion ( $T_{\mathrm{ini}} \mathrm{s}$ of $658 \pm 47,708 \pm 72$, and $737 \pm 89 \mathrm{~ms})$ and early occlusion blocks $\left(T_{\mathrm{ini}} \mathrm{S}\right.$ of $455 \pm 32 \mathrm{~ms}, 474 \pm 49$, and $476 \pm 47 \mathrm{~ms}$ ).

The IBP $\times$ IHP interaction was also significant $[F(2$, $\left.22)=7.67, P<0.005, \eta_{\mathrm{p}}^{2}=0.41\right]$ and post hoc analyses showed that movements from $\mathrm{IHP}_{\text {middle }}$ were initiated earlier for balls approaching from $\operatorname{IBP}_{\text {near }}\left(T_{\text {ini }}=\right.$ $639 \pm 67 \mathrm{~ms})$ than from $\operatorname{IBP}_{\text {far }}\left(T_{\text {ini }}=606 \pm 55 \mathrm{~ms}\right)$, while for the other IHPs there was no effect of IBP $\left(T_{\mathrm{ini}} \mathrm{s}\right.$ of $583 \pm 60$ and $594 \pm 51 \mathrm{~ms}$ for $\mathrm{IHP}_{\text {near }}$ and $653 \pm 71$ and $639 \pm 74 \mathrm{~ms}$ for $\left.\mathrm{IHP}_{\text {far }}\right)$. Moreover, for $\mathrm{IBP}_{\text {near }}$ the difference between $\mathrm{IHP}_{\text {middle }}$ and $\mathrm{IHP}_{\text {far }}$ was not significant, while for $\mathrm{IBP}_{\text {far }}$ the difference between $\mathrm{IHP}_{\text {near }}$ and $\mathrm{IHP}_{\text {middle }}$ was not significant. Finally, the IP $\times$ IHP interaction for $T_{\mathrm{ini}}\left[F(6,66)=8.92, P<0.001, \eta_{\mathrm{p}}^{2}=0.45\right]$ revealed that the effect of IHP (later initiation from $\mathrm{IHP}_{\text {near }}$ than $\mathrm{IHP}_{\text {middle }}$ and $\left.\mathrm{IHP}_{\text {far }}\right)$ was only present for IP1 $\left(T_{\mathrm{ini}} \mathrm{s}\right.$ of $594 \pm 53,650 \pm 68$, and $661 \pm 58 \mathrm{~ms})$ and IP2 $\left(T_{\mathrm{ini}} \mathrm{s}\right.$ of $533 \pm 76,625 \pm 79 \mathrm{~ms}$, and $662 \pm 70 \mathrm{~s} ; T_{\mathrm{ini}} \mathrm{s}$ of $603 \pm 66,606 \pm 65$, and $646 \pm 96 \mathrm{~ms}$ for IP3, and $623 \pm 54,609 \pm 48$, and $615 \pm 78 \mathrm{~ms}$ for IP4). In addition, an effect of IP (later initiation for balls approaching IP2 than for balls approaching IP3 or IP4) was only significant when the hand started at $\mathrm{IHP}_{\text {near }}$.

\section{Average movement bias $\left(\Delta X_{h-a v}\right)$}

The effect of Occlusion for $\Delta X_{\mathrm{h}-\mathrm{av}}$ revealed a larger leftward bias in the hand trajectory for late occlusion than for early occlusion. The effect of IBP showed that the trajectory deviated more leftward when balls approached from $\mathrm{IBP}_{\text {near }}$ than when balls approached from IBP $_{\text {far }}$. The effect of IP revealed a significantly larger leftward bias in the trajectory when balls passed further to the right (all differences significant). Post hoc analyses of the IBP $\times$ IHP interaction $\left[F(6,66)=4.01, P<0.05, \eta_{\mathrm{p}}^{2}=0.27\right]$ indicated that the main effect of IBP was only significant when 
Table 1 Main effects for "Experiment 1"

\begin{tabular}{|c|c|c|c|c|c|c|}
\hline Effect & $F$ value & $\eta_{\mathrm{p}}^{2}$ & $\begin{array}{l}\text { Level } 1 \\
\text { No occlusion } \\
\text { IBP }_{\text {near }} \\
\text { IP1 } \\
\text { IHP }_{\text {near }}\end{array}$ & $\begin{array}{l}\text { Level } 2 \\
\text { Late occlusion } \\
\text { IBP }_{\text {far }} \\
\text { IP2 } \\
\text { IHP }_{\text {middle }}\end{array}$ & $\begin{array}{l}\text { Level } 3 \\
\text { Early occlusion } \\
\text { IP3 } \\
\text { IHP }_{\text {far }}\end{array}$ & Level 4 \\
\hline \multicolumn{7}{|l|}{$T_{\mathrm{ini}}$} \\
\hline $\mathrm{Occl}^{\mathrm{a}}$ & $F(2,22)=103.65^{* * *}$ & 0.90 & $687 \pm 93 \mathrm{~ms}$ & $701 \pm 59 \mathrm{~ms}$ & $468 \pm 42 \mathrm{~ms}$ & \\
\hline $\mathrm{IP}^{\mathrm{b}}$ & $F(3,33)=3.51^{*}$ & 0.24 & $635 \pm 51 \mathrm{~ms}$ & $606 \pm 67 \mathrm{~ms}$ & $619 \pm 69 \mathrm{~ms}$ & $616 \pm 54 \mathrm{~ms}$ \\
\hline $\mathrm{IHP}^{\mathrm{c}}$ & $F(2,22)=16.24^{* * *}$ & 0.60 & $588 \pm 52 \mathrm{~ms}$ & $622 \pm 59 \mathrm{~ms}$ & $646 \pm 71 \mathrm{~ms}$ & \\
\hline \multicolumn{7}{|l|}{$\Delta X_{\mathrm{h}-\mathrm{av}}$} \\
\hline Occl & $F(2,22)=8.96^{* *}$ & 0.44 & $-1.8 \pm 1.3 \mathrm{~cm}$ & $-2.6 \pm 1.3 \mathrm{~cm}$ & $-1.5 \pm 1.1 \mathrm{~cm}$ & \\
\hline $\mathrm{IBP}^{\mathrm{d}}$ & $F(1,11)=5.48^{*}$ & 0.33 & $-2.2 \pm 1.3 \mathrm{~cm}$ & $-1.7 \pm 1.1 \mathrm{~cm}$ & & \\
\hline IP & $F(1.6,17.1)=62.52^{* * *}$ & 0.85 & $0.5 \pm 1.4 \mathrm{~cm}$ & $-1.2 \pm 1.4 \mathrm{~cm}$ & $-2.6 \pm 1.4 \mathrm{~cm}$ & $-4.6 \pm 1.4 \mathrm{~cm}$ \\
\hline \multicolumn{7}{|l|}{$\mathrm{CE}_{\mathrm{HPI}}$} \\
\hline Occl & $F(2,22)=5.52^{*}$ & 0.33 & $-1.0 \pm 1.3 \mathrm{~cm}$ & $-1.9 \pm 1.4 \mathrm{~cm}$ & $-1.1 \pm 1.2 \mathrm{~cm}$ & \\
\hline IBP & $F(1,11)=11.86^{* *}$ & 0.52 & $-1.1 \pm 1.2 \mathrm{~cm}$ & $-1.6 \pm 1.2 \mathrm{~cm}$ & & \\
\hline IP & $F(1.5,17.0)=44.64^{* * *}$ & 0.80 & $0.8 \pm 1.7 \mathrm{~cm}$ & $-0.6 \pm 1.4 \mathrm{~cm}$ & $-1.4 \pm 1.3 \mathrm{~cm}$ & $-4.1 \pm 1.5 \mathrm{~cm}$ \\
\hline IHP & $F(2,22)=4.85^{*}$ & 0.31 & $-1.9 \pm 1.1 \mathrm{~cm}$ & $-1.2 \pm 1.2 \mathrm{~cm}$ & $-0.9 \pm 1.7 \mathrm{~cm}$ & \\
\hline \multicolumn{7}{|c|}{$\Delta X_{\mathrm{h}-\text { early }}$} \\
\hline Occl & $F(1,11)=6.48^{*}$ & 0.37 & $-2.2 \pm 1.4 \mathrm{~cm}$ & $-3.1 \pm 1.4 \mathrm{~cm}$ & & \\
\hline IBP & $F(1,11)=10.31^{* *}$ & 0.48 & $-3.2 \pm 1.7 \mathrm{~cm}$ & $-2.1 \pm 1.0 \mathrm{~cm}$ & & \\
\hline IP & $F(1.6,17.9)=25.70^{* * * *}$ & 0.70 & $-0.1 \pm 1.6 \mathrm{~cm}$ & $-2.2 \pm 1.4 \mathrm{~cm}$ & $-3.4 \pm 1.8 \mathrm{~cm}$ & $-4.7 \pm 2.0 \mathrm{~cm}$ \\
\hline IHP & $F(1.2,12.9)=3.71^{*}$ & 0.25 & $-1.8 \pm 1.8 \mathrm{~cm}$ & $-2.7 \pm 1.2 \mathrm{~cm}$ & $-3.5 \pm 2.3 \mathrm{~cm}$ & \\
\hline
\end{tabular}

a Occl Occlusion

b $I P$ interception point

c $I H P$ initial hand position

d IBP initial ball position

Under levels $1-4$ the values corresponding to the respective levels of the factor in question are presented (mean \pm SD). ${ }^{*} P<0.05 ;{ }^{* *} P<0.01$; ${ }^{* * * *} P<0.001$

the hand started at $\mathrm{IHP}_{\text {middle }}\left(\Delta X_{\mathrm{h}-\mathrm{av}} \mathrm{s}\right.$ of $-2.5 \pm 1.5$ and $-1.7 \pm 0.9 \mathrm{~cm} ; \Delta X_{\mathrm{h}-\mathrm{av}}$ was $-2.3 \pm 1.2$ and $-1.9 \pm 1.5 \mathrm{~cm}$ for $\mathrm{IHP}_{\text {near, }}$ and $-1.7 \pm 1.6$ and $-1.6 \pm 1.8 \mathrm{~cm}$ for $\left.\mathrm{IHP}_{\text {far }}\right)$. In addition, for balls approaching from $\mathrm{IBP}_{\text {near }}$ hand movements from $\mathrm{IHP}_{\text {middle }}$ were biased more to the left than those from $\mathrm{IHP}_{\text {far }}$.

\section{Hand position at interception $\left(C E_{H P I}\right)$}

Post hoc analyses of the effect of Occlusion showed that the hand ended significantly more to the left when the last part of the ball flight was occluded compared to no and early occlusion. In addition, in contrast with the other variables, the hand position at interception deviated more leftward for balls approaching from $\mathrm{IBP}_{\text {far }}$ than from IBP $_{\text {near }}$ Post hoc analyses of the effect of IP for $\mathrm{CE}_{\mathrm{HPI}}$ revealed that the hand ended more leftward the further to the right the ball passed the participant (all differences significant, except IP2-IP3). Post hoc analyses of the effect of IHP did not yield any significant differences, but it seemed to reflect a more leftward hand position at the catch when it started at $\mathrm{IHP}_{\text {near }}$.

The significant IP $\times$ IHP interaction for $\mathrm{CE}_{\mathrm{HPI}}[F(6$, $\left.66)=3.91, P<0.005, \eta_{\mathrm{p}}^{2}=0.26\right]$ was related to the fact that there was only a significant effect of IHP for IP4 $\left(\mathrm{CE}_{\mathrm{HPI}} \mathrm{S}\right.$ of $-5.1 \pm 2.1,-4.6 \pm 1.7$, and $-4.0 \pm 1.8 \mathrm{~cm}$, respectively; more leftward $\mathrm{CE}_{\mathrm{HPI}}$ for $\mathrm{IHP}_{\text {near }}$ than for $\mathrm{IHP}_{\text {middle }}$ and $\mathrm{IHP}_{\text {far }}$ ). For IP1, IP2, and IP3 no effect of IHP was obtained (IP1: $\mathrm{CE}_{\mathrm{HPI}} \mathrm{S}$ of $0.1 \pm 1.6,0.5 \pm 1.5$, and $\quad 1.0 \pm 1.6 \mathrm{~cm} ; \quad \mathrm{IP} 2: \mathrm{CE}_{\mathrm{HPI}} \mathrm{S}$ of $-0.9 \pm 1.3$, $-1.6 \pm 1.8, \quad$ and $-1.1 \pm 1.7 \mathrm{~cm} ; \quad \mathrm{IP} 3: \mathrm{CE}_{\mathrm{HPI}} \mathrm{S}$ of $-2.5 \pm 1.9, \quad-2.7 \pm 1.5$, and $-2.5 \pm 2.2 \mathrm{~cm})$. For $\mathrm{IHP}_{\text {middle }}$ and $\mathrm{IHP}_{\text {far }}$ the effect of IP matched the main effect (i.e., only the difference between IP2 and IP3 not significant), whereas for $\mathrm{IHP}_{\text {near }}$ all differences were significant except IP1-IP2. 

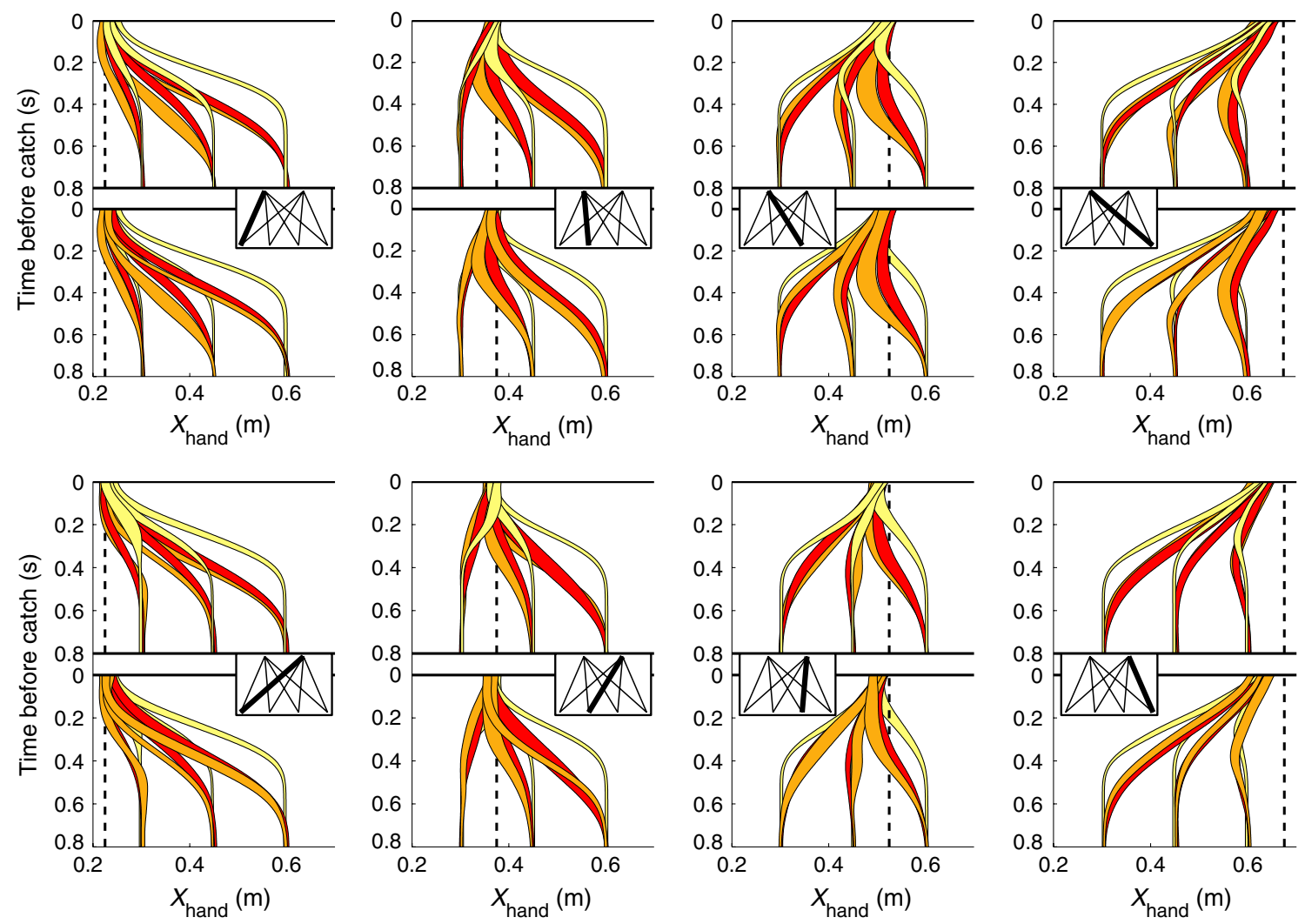

Fig. 3 Time-averaged hand movements ( \pm SE per sample) from $0.8 \mathrm{~s}$ before contact until contact for the eight ball trajectories (the top-view of which is schematically presented in the inset in each panel) for the three initial hand positions and for the three occlusion conditions (red no occlusion; yellow early occlusion; orange late occlusion) in "Experiment 1". To compute the average movements for each condition, the movements for each participant were averaged over the two repetitions (unless one of these was omitted from the analyses)

\section{Early movement bias $\left(\Delta X_{h-e a r l y}\right)$}

As mentioned, inspection of the data suggested that late occlusion affected the movements already early on, possibly even before the onset of the occlusion (cf. Fig. 3). This suggestion was examined by means of $\Delta X_{\mathrm{h}-\text { early. The }}$ effect of Occlusion showed that $\Delta X_{\mathrm{h}-\text { early }}$ was more leftward for late than for no occlusion. The effect of IBP revealed a larger initial leftward bias in balls approaching from $\mathrm{IBP}_{\text {near }}$ than from $\mathrm{IBP}_{\text {far }}$. These two effects also interacted $\left[F(1,11)=7.63, P<0.05, \eta_{\mathrm{p}}^{2}=0.41\right.$; Fig. 4], showing that the effect of occlusion was only present for balls approaching from $\mathrm{IBP}_{\text {near }}$ (see also Fig. 3, upper panels) and that the effect of IBP was only significant for late occlusion.

Post hoc analyses of the effect of IP showed that the early hand movements deviated more leftward the further to the right the ball passed (all differences significant). This effect varied slightly over the IHPs, as shown by the $\mathrm{IP} \times \mathrm{IHP}$ interaction $[F(6,66)=3.32, \quad P<0.01$,

and the resulting movements were subsequently averaged over participants. Note that all movements are presented twice, in two subplots directly on top of each other. To enhance the visibility of the movements the order of plotting the different occlusion conditions and initial hand positions is reversed for these two presentations. In each panel, the vertical dotted line indicates the ball's passing position

$\left.\eta_{\mathrm{p}}^{2}=0.23\right]$. For $\mathrm{IHP}_{\text {near }}$ the early hand movements were biased more leftward for ball passing at IP4 than at the other IPs $\left(\Delta X_{\mathrm{h}-\text { earlys }}\right.$ of $0.0 \pm 1.7,-0.9 \pm 1.1,-2.0 \pm$ 2.4 , and $-4.2 \pm 3.5 \mathrm{~cm})$, for $\mathrm{IHP}_{\text {middle }}$ it was less leftward for balls passing at IP1 than at the other IPs $\left(\Delta X_{\mathrm{h}-\text { early }} \mathrm{s}\right.$ of $-0.2 \pm 1.9,-2.9 \pm 2.1,-3.6 \pm 1.7$, and $-4.3 \pm$ $2.3 \mathrm{~cm}$ ), while for $\mathrm{IHP}_{\text {far }}$ only the difference between IP3 and IP4 did not reach significance $\left(\Delta X_{\mathrm{h}-\text { early }} \mathrm{s}\right.$ of $-0.1 \pm$ $2.5,-2.8 \pm 2.4,-5.4 \pm 3.0$, and $-5.7 \pm 2.9 \mathrm{~cm})$. There were no effects of IHP for any IP.

\section{Experiment 2: randomized Occlusion conditions}

Success rates differed significantly between the Occlusion conditions $\left[\chi^{2}(2,12)=18.78, P<0.001\right]$; post hoc analyses showed that catching success was lower for late occlusion (82.1\%) than for no and early occlusion (93.2 and $93.1 \%$, respectively). Nearly all of the effects of IBP, IP, and IHP were similar to those obtained for "Experiment 1". For the sake of brevity, we therefore only discuss the effects 


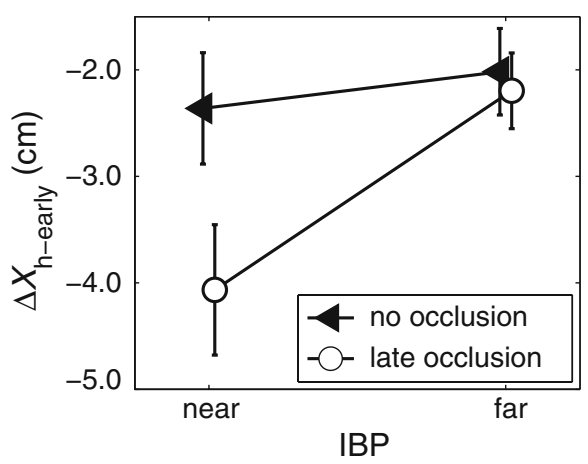

Fig. 4 Average values of the early movement bias $\left(\Delta X_{\mathrm{h}-\text { early }}\right)$ for no and late occlusion for the near and far initial ball position (IBP ${ }_{\text {near }}$ and $\left.\mathrm{IBP}_{\text {far }}\right)$ in "Experiment 1". Error bars indicate SE

and interactions including the factor Occlusion in relation to the corresponding results obtained for "Experiment 1". Table 2 contains the $F$ values and $\eta_{\mathrm{p}}^{2}$ s for all significant main effects of all dependent variables in "Experiment 2", as well as the average values of the different levels.

As in "Experiment 1 ", $T_{\text {ini }}$ was significantly affected by Occlusion $\left[F(1.2,13.5)=349.24, P<0.001, \eta_{\mathrm{p}}^{2}=0.97\right]$, showing that movements were initiated later with early occlusion, compared to no and late occlusion. Also, the Occlusion $\times$ IHP interaction $[F(4,44)=4.52, P<0.005$, $\eta_{\mathrm{p}}^{2}=0.29$; Fig. 5a] showed that for late occlusion, movements were initiated earlier from $\mathrm{IHP}_{\text {far }}$ than from $\mathrm{IHP}_{\text {near }}$ and $\mathrm{IHP}_{\text {middle. }}$. Whereas the effect of Occlusion for $\Delta X_{\mathrm{h}-\mathrm{av}}$ in "Experiment 1" mainly reflected the larger leftward deviation with late occlusion, in "Experiment 2" it was due to a smaller leftward bias for early occlusion than for no and late occlusion. Although this effect also interacted with $\operatorname{IHP}\left[F(4,44)=2.78, P<0.05, \eta_{\mathrm{p}}^{2}=0.20\right.$; Fig. 5b], post hoc analyses did not reveal any significant deviations from these respective main effects.

Whereas $\mathrm{CE}_{\mathrm{HPI}}$ was clearly more leftward for late occlusion than for no and early occlusion in "Experiment 1 ", the effect of Occlusion failed to reach significance in "Experiment 2". The Occlusion $\times$ IP interaction $[F(6$, 66) $\left.=3.72, P<0.005, \eta_{\mathrm{p}}^{2}=0.26\right]$ revealed that for balls passing at IP1 the hand deviated more to the right of the IP with late occlusion than without occlusion, and for balls passing at IP2 the hand deviated more to the left without occlusion than with early occlusion. For all Occlusion levels $\mathrm{CE}_{\mathrm{HPI}}$ did not differ between IP2 and IP3, while for early occlusion the difference between IP1 and IP2 also did not reach significance (cf. Fig. 6). The Occlusion $\times \mathrm{IBP} \times \mathrm{IP}$ interaction $[F(6,66)=2.37, P<0.05$, $\eta_{\mathrm{p}}^{2}=0.18$; Fig. 6a, b] showed that the reported Occlusion effects for IP1 and IP2 were only significant for balls approaching from $\mathrm{IBP}_{\text {near. }}$. Moreover, for early occlusion $\mathrm{CE}_{\mathrm{HPI}}$ was more leftward for balls approaching IP2 from $\mathrm{IBP}_{\text {far }}$ than from $\mathrm{IBP}_{\text {near }}$. Similarly, the Occlusion $\times$
IP $\times$ IHP interaction $[F(12,132)=2.03, \quad P<0.05$, $\eta_{\mathrm{p}}^{2}=0.16$; Fig. $\left.6 \mathrm{c}-\mathrm{e}\right]$ showed that the reported Occlusion effects for IP1 and IP2 were only significant when the hand started at $\mathrm{IHP}_{\text {far }}$, and that without occlusion for balls passing at IP1 $\mathrm{CE}_{\mathrm{HPI}}$ was more rightward when the hand started at $\mathrm{IHP}_{\text {far }}$ than when its started at $\mathrm{IHP}_{\text {near }}$. The most striking observation of "Experiment 2" was that effects of Occlusion were entirely absent for $\Delta X_{\mathrm{h}-\text { early, showing }}$ that, in contrast to the results of "Experiment 1", the early movement bias was statistically the same for no $\left(\Delta X_{\mathrm{h}-\text { early }}=-3.8 \pm 2.7 \mathrm{~cm}\right)$ and late occlusion $\left(\Delta X_{\mathrm{h}-\text { early }}=-3.8 \pm 2.5 \mathrm{~cm}\right)$.

\section{Effects of previous trials}

The ANOVAs testing the effect of previous trials during the randomized design showed that $\mathrm{CE}_{\mathrm{HPI}}$ was influenced by the offset time of vision in the previous trial $[F(1$, $\left.547)=4.94, P<0.05, \eta_{\mathrm{p}}^{2}=0.006\right]$, showing that the hand position at interception deviated more leftward in trials preceded by a late occlusion trial $(-0.7 \pm 1.0 \mathrm{~cm})$ than in those preceded by a no or early occlusion trial $(-0.6 \pm 1.4 \mathrm{~cm})$. Both the average and early movement bias were influenced by the onset time of vision in the preceding trial $\left[\Delta X_{\mathrm{h}-\mathrm{av}}: F(1,547)=5.53, P<0.05\right.$, $\eta_{\mathrm{p}}^{2}=0.007 ; \quad \Delta X_{\mathrm{h}-\text { early }}: \quad F(1, \quad 547)=5.31, \quad P<0.05$, $\left.\eta_{\mathrm{p}}^{2}=0.010\right]$, showing that these were more leftward in trials preceded by an early occlusion trial $\left(\Delta X_{\mathrm{h}-\mathrm{av}}=\right.$ $\left.-2.1 \pm 1.7 \mathrm{~cm} ; \Delta X_{\mathrm{h}-\text { early }}=-4.1 \pm 2.4 \mathrm{~cm}\right)$ than in trials preceded by a no or late occlusion trial $\left(\Delta X_{\mathrm{h}-\mathrm{av}}=\right.$ $\left.-1.8 \pm 1.6 \mathrm{~cm} ; \quad \Delta X_{\mathrm{h}-\text { early }}=-3.7 \pm 2.8 \mathrm{~cm}\right) . \quad$ Although very small, these effects showed that our participants changed their control strategy in such a way the leftward bias increased late in the movement (after a late occlusion trial) and early in the movement (after an early occlusion trial).

\section{Discussion}

In the present study, we examined catching movements when specific parts of the ball trajectories were occluded. We constrained the hand movements to a lateral direction to focus on the control of hand position (i.e., the moment of interception was determined by the moment the ball passed the lateral hand movement axis). The pendular ball trajectories used generated mainly downward visual motion initially; the lateral motion component only became apparent later in the trajectory (Fig. 1). We occluded the initial part of these trajectories to examine the proposed relation between the lateral visual acceleration and the leftward bias in the hand movement (Dessing et al. 2005; see also Brouwer et al. 2002, 2003, 2005; de Lussanet et al. 
Table 2 Main effects for "Experiment 2"

\begin{tabular}{|c|c|c|c|c|c|c|}
\hline Effect & $F$ value & $\eta_{\mathrm{p}}^{2}$ & $\begin{array}{l}\text { Level } 1 \\
\text { No occlusion } \\
\text { IBP }_{\text {near }} \\
\text { IP1 } \\
\text { IHP }_{\text {near }}\end{array}$ & $\begin{array}{l}\text { Level } 2 \\
\text { Late occlusion } \\
\mathrm{IBP}_{\text {far }} \\
\text { IP2 } \\
\text { IHP }_{\text {middle }}\end{array}$ & $\begin{array}{l}\text { Level } 3 \\
\text { Early occlusion } \\
\text { IP3 } \\
\mathrm{IHP}_{\text {far }}\end{array}$ & Level 4 \\
\hline \multicolumn{7}{|l|}{$T_{\mathrm{ini}}$} \\
\hline $\mathrm{Occl}^{\mathrm{a}}$ & $F(1.2,13.5)=349.24^{* * *}$ & 0.97 & $731 \pm 78 \mathrm{~ms}$ & $721 \pm 85 \mathrm{~ms}$ & $471 \pm 42 \mathrm{~ms}$ & \\
\hline $\mathrm{IBP}^{\mathrm{b}}$ & $F(1,11)=6.44^{*}$ & 0.37 & $649 \pm 74 \mathrm{~ms}$ & $632 \pm 61 \mathrm{~ms}$ & & \\
\hline $\mathrm{IHP}^{\mathrm{c}}$ & $F(2,22)=8.33^{* *}$ & 0.43 & $622 \pm 63 \mathrm{~ms}$ & $642 \pm 72 \mathrm{~ms}$ & $659 \pm 74 \mathrm{~ms}$ & \\
\hline \multicolumn{7}{|l|}{$\Delta X_{\mathrm{h}-\mathrm{av}}$} \\
\hline Occl & $F(1.4,15.4)=37.67^{* * *}$ & 0.77 & $-2.5 \pm 1.8 \mathrm{~cm}$ & $-2.4 \pm 1.8 \mathrm{~cm}$ & $-0.8 \pm 1.1 \mathrm{~cm}$ & \\
\hline $\mathrm{IP}^{\mathrm{d}}$ & $F(1.4,15.2)=43.78^{* * *}$ & 0.80 & $-0.1 \pm 1.8 \mathrm{~cm}$ & $-1.4 \pm 1.8 \mathrm{~cm}$ & $-2.2 \pm 1.7 \mathrm{~cm}$ & $-4.0 \pm 1.6 \mathrm{~cm}$ \\
\hline IHP & $F(1.3,14.1)=4.50^{*}$ & 0.29 & $-1.2 \pm 1.7 \mathrm{~cm}$ & $-2.1 \pm 1.4 \mathrm{~cm}$ & $-2.4 \pm 2.1 \mathrm{~cm}$ & \\
\hline \multicolumn{7}{|l|}{$\mathrm{CE}_{\mathrm{HPI}}$} \\
\hline IP & $F(3,33)=48.30^{* * * *}$ & 0.81 & $1.5 \pm 1.2 \mathrm{~cm}$ & $0.0 \pm 1.8 \mathrm{~cm}$ & $-0.7 \pm 1.6 \mathrm{~cm}$ & $-3.4 \pm 1.5 \mathrm{~cm}$ \\
\hline IHP & $F(2,22)=6.72^{* *}$ & 0.38 & $-1.1 \pm 1.4 \mathrm{~cm}$ & $-0.6 \pm 1.3 \mathrm{~cm}$ & $-0.2 \pm 1.4 \mathrm{~cm}$ & \\
\hline \multicolumn{7}{|c|}{$\Delta X_{\mathrm{h}-\text { early }}$} \\
\hline IBP & $F(1,11)=8.25^{* *}$ & 0.43 & $-4.5 \pm 2.9 \mathrm{~cm}$ & $-3.2 \pm 2.5 \mathrm{~cm}$ & & \\
\hline IP & $F(1.5,16.9)=33.89^{* * * *}$ & 0.76 & $-1.0 \pm 3.5 \mathrm{~cm}$ & $-3.2 \pm 3.1 \mathrm{~cm}$ & $-4.6 \pm 2.2 \mathrm{~cm}$ & $-6.5 \pm 2.5 \mathrm{~cm}$ \\
\hline \multicolumn{7}{|c|}{ a $O c c l$ Occlusion } \\
\hline \multicolumn{7}{|c|}{ b $I H P$ initial hand position } \\
\hline \multicolumn{7}{|c|}{${ }^{\mathrm{c}} I B P$ initial ball position } \\
\hline \multicolumn{7}{|c|}{ d $I P$ interception point } \\
\hline
\end{tabular}
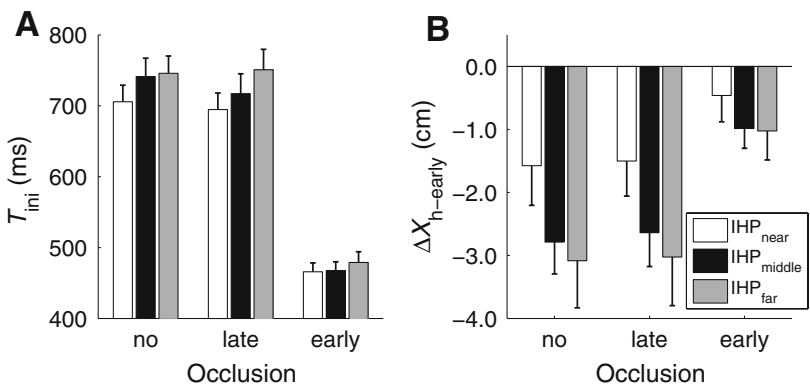

Fig. 5 Average values of the moment of initiation $\left(T_{\text {ini }}\right.$ a) and the early movement bias $\left(\Delta X_{\mathrm{h}-\text { early }} \mathbf{b}\right)$ for the three occlusion conditions and the three initial hand positions (IHPS) in "Experiment 2". Error bars indicate SE

2004). This relation would result from an underestimation of the future rightward visual ball motion because rightward visual acceleration is not (fully) taken into account. Early occlusion was expected to delay movement initiation, because balls became visible later. This in turn should yield a smaller leftward movement bias, because any estimate of future ball motion based on only position and velocity information improves during ball approach. We occluded the final part of the ball trajectories to examine the strategies and quality of motion extrapolation for catching. Both occlusion conditions were compared to caching without occlusion. We first presented the occlusion conditions in blocks, but the observations of that experiment motivated the inclusion of a control experiment in which the occlusion conditions were presented in randomized order, to asses whether the effects in the first experiment reflected adaptations in the control strategy. As will become apparent in the next sections, such adaptations indeed occurred and proved vital in understanding the specific roles of lateral visual acceleration and motion extrapolation in catching.

\section{Lateral visual acceleration}

As expected early occlusion delayed movement initiation. However, the leftward movement bias did not decrease with this later initiation when the occlusion conditions were presented in blocks ("Experiment 1"); in "Experiment 2" (with occlusion conditions presented in random order), however, the decrease was observed. The latter result is consistent with our suggestion that the leftward movement biases in our set-up depend on the lateral visual acceleration generated by our ball trajectories. Apparently, 
Fig. 6 Average values of the constant error of the hand position at interception $\left(C E_{H P I}\right)$ for the three occlusion conditions and four interception points $(I P s)$, presented separately for the two initial ball positions $\left(\mathbf{a} \mathrm{IBP}_{\text {near }} ; \mathbf{b} \mathrm{IBP}_{\text {far }}\right)$ and for the three initial hand positions $\left(\mathbf{c} \mathrm{IHP}_{\text {near }} ; \mathbf{d ~ I H P}_{\text {middle }}\right.$; e $\left.\mathrm{IHP}_{\text {far }}\right)$. Error bars indicate SE
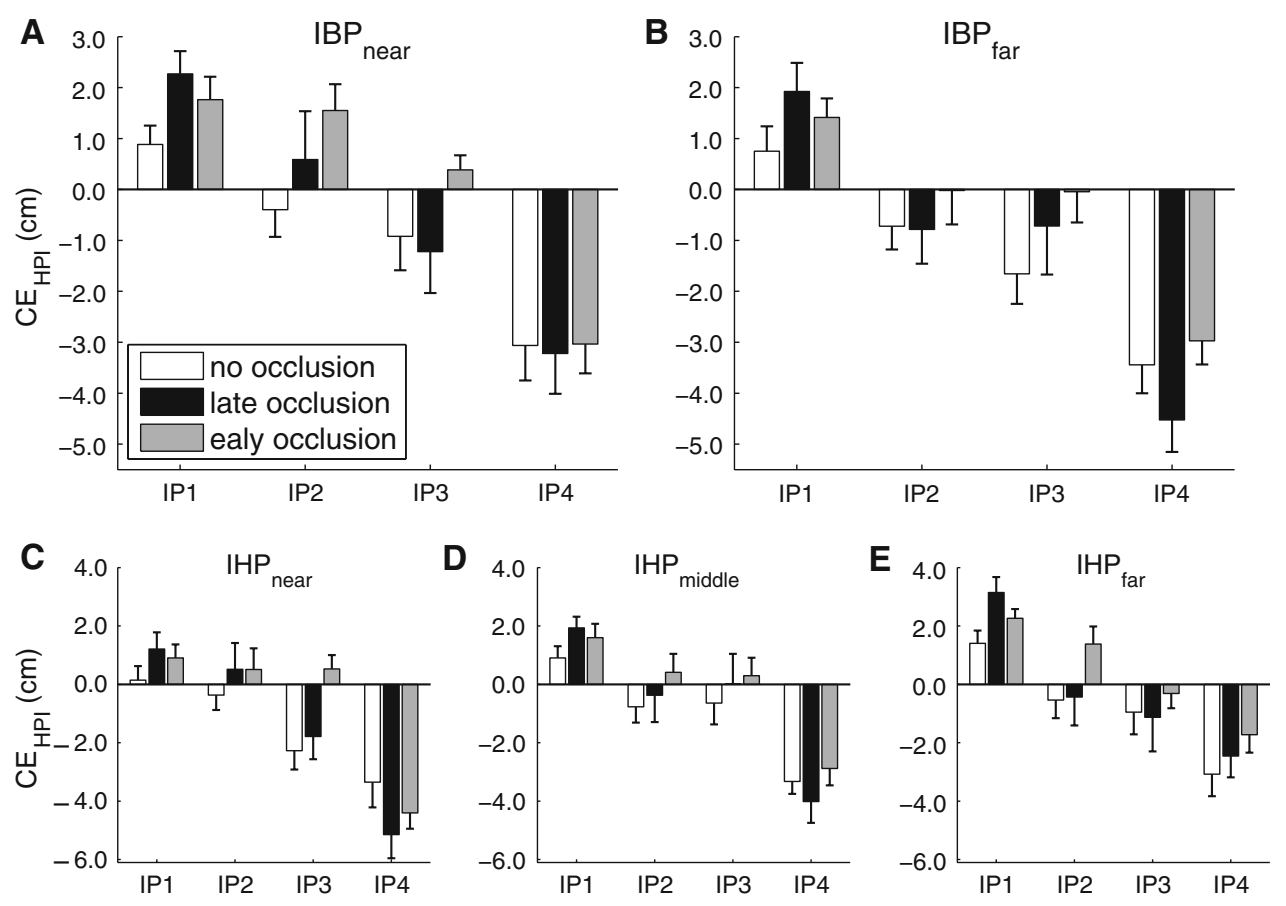

during "Experiment 1" this dependency was masked by adaptations of the control strategy provoked by the blocked presentation. This suggestion is backed up by the observation of trial-by-trial adaptations in "Experiment 2", resulting in a larger leftward movement bias in trials preceded by an early occlusion trial. Next, we discuss the adaptations that most likely contribute to this effect.

Manual interception has been proposed to involve a position-servo of hand position relative to the current (Peper et al. 1994) or extrapolated target position (Smeets and Brenner 1995; see also Tresilian 2005). The former proposal, however, has also been extended to involve ball velocity information, which renders these options mathematically (and thus behaviorally) equivalent in the presence of continuous movement adjustments (Dessing et al. 2005). Therefore, although the present study touches on this issue, it does not allow making a choice between these options (which, in our view, is a matter that can only be resolved using neural evidence). For catching this position-servo can be captured by:

$\dot{X}_{\text {hand }}=\omega_{\mathrm{VM}}\left(\left(X_{\text {ball }}+\omega_{\text {vel }} \times \dot{X}_{\text {ball }}\right)-X_{\text {hand }}\right)$

Here, hand velocity $\left(\dot{X}_{\text {hand }}\right)$ is determined by the difference between hand position $\left(X_{\text {hand }}\right)$ and the extrapolated ball position $\left(X_{\text {ball }}+\omega_{\text {vel }} \times \dot{X}_{\text {ball }}\right)$. Factor $\omega_{\mathrm{VM}}$ represents the strength of attraction or visuomotor gain, while factor $\omega_{\text {vel }}$ represents the velocity gain, which is a function of the extrapolation window (e.g., the visuomotor delay, Mrotek and Soechting 2007b, or the time remaining before contact, Dessing et al. 2005). For rightward accelerating balls the leftward movement bias increases for smaller $\omega_{\text {vel }} \mathrm{s}$, because the hand will be attracted to a more leftward position (i.e., rightward visual motion is underestimated more). Larger $\omega_{\mathrm{VM}} \mathrm{S}$ will do the same if the used $\omega_{\text {vel }}$ does not fully compensate for the low sensitivity to visual acceleration, because the hand will be attracted stronger to a position that already induces a leftward bias. In principle, therefore, adaptations in the velocity gain and/or visuomotor gain may have masked the effects of early occlusion in "Experiment 1 ". Both options are discussed next.

We deem it unlikely that our results were induced by adaptations in the velocity gain. This conclusion follows from a comparison with the results of de Lussanet et al. (2001, 2002). These authors reported effects of target velocity in previous trials on movement biases, from which they suggested that the motion extrapolation process uses the target velocity of the previous trial (see also Gray 2002; Smeets and Brenner 1995). In our task, however, it is likely that the actually available velocity information is used, because sufficient time was always available (Brenner et al. 1998; Dessing et al. 2005). Still, these effects may reflect a scaling of the velocity gain with the preceding target's velocity. Given that the average visual ball velocity during early occlusion trials was higher than during the other occlusion trials (i.e., the slow part was occluded), the larger leftward bias for trials following an early occlusion trial would point to an inverse scaling (i.e., a lower velocity gain for higher average visual target velocity in the preceding trial). However, given that the effects reported by de Lussanet et al. $(2001,2002)$ were in the opposite direction, a different explanation was needed. 
It is well established in the literature on manual interception that hand velocity (and movement time) depends on target velocity (called velocity-coupling; Brenner et al. 1998; Brouwer et al. 2000, 2002, 2005; Carnahan and McFadyen 1996; Fayt et al. 1997; Smeets and Brenner 1995; van Donkelaar et al. 1992). This velocity-coupling may reflect a dependency of the visuomotor gain on visual target velocity (Dessing et al. 2002), reminiscent of variations in the visuomotor gain of the smooth pursuit system as a function of target velocity (Churchland and Lisberger 2002; Krauzlis and Lisberger 1994; Nuding et al. 2008; Robinson 1965; Tanaka and Lisberger 2001). Importantly, recent findings also suggest that for smooth pursuit this gain seems to be updated on a trial-by-trial basis (Tabata et al. 2008) in a direction similar to the effects of the preceding target's velocity observed here. Adaptations of the visuomotor gain can thus explain the absence of effects of early occlusion in "Experiment 1" and also the larger leftward movement biases (for no and late occlusion) in "Experiment 2". 1

Of course, the control of interception is not identical to that of smooth pursuit, because pursuit can be considered to involve only a velocity-servo (Churchland and Lisberger 2002), while interception depends on a position-servo (Peper et al. 1994; Smeets and Brenner 1995) in which target velocity also plays a role (de Lussanet et al. 2004; Dessing et al. 2005; van Donkelaar et al. 1992; Eq. 1). However, cross-links exist between the oculomotor and forelimb control systems (e.g., Engel and Soechting 2003; Ilg and Schumann 2007; Lazzari et al. 1997; see also Kruse et al. 2002) and the present results suggest that the dynamic visuomotor gain control proposed for the former is also employed for the latter.

\section{Motion extrapolation}

We included the late occlusion condition to examine the motion extrapolation process in catching, and specifically to examine how this process accounts for the lateral visual acceleration in the final part of the ball trajectory. Late occlusion had considerable effects during the blocked presentation, in that the hand position deviated considerably leftward at the moment of interception. This bias, however, was already present at the onset of late occlusion (compared to no occlusion) for balls approaching from IBP $_{\text {near }}\left(\Delta X_{\mathrm{h}-\text { early }} ;\right.$ Fig. 4$)$. These effects were absent in "Experiment 2", although late occlusion still affected the hand position at interception for balls passing at IP1 (i.e.,

\footnotetext{
1 Tentatively, the visuomotor gain could be a vectorial quantity, introducing task-specific variations in the preferred movement direction. This proposal may well provide an alternative interpretation of the results of de Lussanet et al. (2001, 2002).
}

more rightward for late occlusion). In general, the movement biases were more leftward when the occlusion conditions were presented in random order (compare Tables 1,2). These results show that in both experiments ball motion was extrapolated reasonably well over period of $400 \mathrm{~ms}$, even in the presence of visual acceleration (due to 3D curvilinear target motion). In "Experiment 1", however, the blocked presentation apparently prevented entirely accurate extrapolation, because the to-be-extrapolated part was never visible (whereas it was during the randomized presentation; cf. Mrotek and Soechting 2007a). Because the visual information available until the occlusion started in the late occlusion condition did not differ from the no occlusion condition, these effects must reflect adaptations in how (instead of which) visual information was used to control the catching movements. Short-term adaptations in the motion extrapolation process were indeed suggested by the larger leftward final movement bias in trials preceded by a late occlusion trial in "Experiment 2 ".

Movement biases were smallest in the no occlusion block, suggesting that lateral visual acceleration was better accounted for in this condition. In the late occlusion block our participants apparently could not fully account for the lateral visual acceleration in that condition, as evident from the observed leftward bias (particularly for balls with a high lateral velocity, i.e., those approaching from $\mathrm{IBP}_{\text {near }}$ ). These results may be accounted for in terms of Eq. 1, in which the extrapolated ball position may be extended to include an entirely non-visual term specifying additional expected displacement (ED):

$X_{\text {ball }}(t+\Delta)=X_{\text {ball }}(t)+\omega_{\text {vel }} \times \dot{X}_{\text {ball }}(t)+\mathrm{ED}$

Here, $t$ refers to time, $\Delta$ is the (arbitrary) extrapolation window, $X_{\text {ball }}(t)$ and $\dot{X}_{\text {ball }}(t)$ the current ball position and velocity, and $\omega_{\mathrm{vel}}$ the velocity gain. The velocity gain may be more relevant when velocity signals are present (i.e., gain modulation of an absent signal is meaningless), while ED may be used to account for known acceleration levels, such as gravity (Lacquaniti and Maioli 1989; Indovina et al. 2005; McIntyre et al. 2001; Zago et al. 2004, 2005, 2008) to fill in for absent visual information. The small leftward bias during the no occlusion block points to a more appropriate $\omega_{\mathrm{vel}}$ and/or ED than during the late occlusion block and than during the randomized presentation (for which they apparently were too low, yielding a larger leftward bias).

Late occlusion seems to require a $\Delta$ in Eq. 2 equal to or larger than $400 \mathrm{~ms}$ (such that the target position at interception is 'known' when the occlusion starts), unless the absent motion signals are 'filled in' using ED. However, targets are continuously tracked with the eyes during interception (Brenner and Smeets 2007; Mrotek and 
Soechting 2007b) and although visual pursuit gain typically reduces during occlusion (Becker and Fuchs 1985; Bennett and Barnes 2003; Churchland et al. 2003; Mrotek and Soechting 2007a), occluded targets are pursued. Indeed, motion-related activity in the frontal eye fields persists during occlusion (Barborica and Ferrera 2003; Xiao et al. 2007). This means that ball position and velocity signals are in principle available from the eye movement system, even though these may underestimate ball displacement during the occlusion. We have previously pointed to a possible role of eye velocity signals in ball velocity coding when interpreting the asymmetric effects of background motion on the lateral hand movements observed in a similar catching experiment (Dessing et al. 2005; see also Whitney and Goodale 2005; Soechting et al. 2001). This suggests that eye position and eye velocity signals may be used for $X_{\text {ball }}(t)$ and $\dot{X}_{\text {ball }}(t)$ in Eq. 2, respectively, which might preclude the need to fill in the absent target motion signals. ${ }^{2}$

\section{Conclusions}

The present study showed that the effects of late and early occlusion on the spatial features of lateral hand movements in catching depend on the order of presentation of the occlusion conditions: late occlusion only had an effect during the blocked presentation, and early occlusion only during the randomized presentation. Moreover, during the randomized presentation, movement biases also were more leftward if the preceding trial was an early occlusion trial. The effects of early occlusion during the randomized presentation showed that the leftward movement bias relates to the rightward visual acceleration inherent to the used ball trajectories, while its absence during the blocked presentation was interpreted to reflect trial-by-trial adaptations in the visuomotor gain, reminiscent of observations for the smooth pursuit system. The movement biases during the late occlusion block were interpreted in terms of an incomplete motion extrapolation (e.g., a reduction of the velocity gain), while the similar final movement bias in the randomized presentation underscored that motion extrapolation was more accurate when the to-be-extrapolated motion was visually perceivable in part of the trials. These

\footnotetext{
${ }^{2}$ Given that hand movements in the present set-up were similar when fixating compared to unconstrained viewing (Dessing et al. unpublished observations, 8 February 2008), motion extrapolation is apparently also accurate when only retinal signals are available. It would be interesting to study combined manipulations of occlusion and fixation or to record eye movements during the occlusion in our set-up. However, the use of liquid crystal glasses for occlusion precludes simultaneous eye movement recordings, implying that such measurements are only possible using a non-head-mounted occlusion method.
}

results underscore that continuous movement adjustments for catching depend not only on visual information, but also on visuomotor adaptations based on non-visual information.

Acknowledgments The authors wish to thank Betteco de Boer for her assistance in running "Experiment 1". This research was made possible by grant 451-05-016 awarded to Joost C. Dessing by the Netherlands Organization for Scientific Research (NWO).

Open Access This article is distributed under the terms of the Creative Commons Attribution Noncommercial License which permits any noncommercial use, distribution, and reproduction in any medium, provided the original author(s) and source are credited.

\section{References}

Barborica A, Ferrera VP (2003) Estimating invisible target speed from neuronal activity in monkey frontal eye field. Nat Neurosci 6:66-74

Batista AP, Buneo CA, Snyder LH, Andersen RA (1999) Reach plans in eye-centered coordinates. Science 285:257-260

Becker W, Fuchs AF (1985) Prediction in the oculomotor system: smooth pursuit during transient disappearance of a visual target. Exp Brain Res 57:562-575

Bennett SJ, Barnes GR (2003) Human ocular pursuit during the transient disappearance of a visual target. J Neurophysiol 90:2504-2520

Bootsma RJ, van Wieringen PCW (1990) Timing an attacking forehand drive in table tennis. J Exp Psychol Hum Percept Perform 16:21-29

Brenner E, Smeets JBJ (2007) Flexibility in intercepting moving objects. J Vis 7:14.1-17

Brenner E, Smeets JBJ, de Lussanet MHE (1998) Hitting moving targets: continuous control of the acceleration of the hand on the basis of the target's velocity. Exp Brain Res 122:467-474

Brouwer AM, Brenner E, Smeets JBJ (2000) Hitting moving objects-the dependency of hand velocity on the speed of the target. Exp Brain Res 133:242-248

Brouwer AM, Brenner E, Smeets JBJ (2002) Hitting moving objects: is target speed used in guiding the hand? Exp Brain Res 143:198-211

Brouwer AM, Middelburg T, Smeets JBJ, Brenner E (2003) Hitting moving targets - a dissociation between the use of the target's speed and direction of motion. Exp Brain Res 152:368-375

Brouwer AM, Brenner E, Smeets JBJ (2005) Hitting moving targets: effects of target speed and dimensions on movement time. Exp Brain Res 165:28-36

Buneo CA, Jarvis MR, Batista AP, Andersen RA (2002) Direct visuomotor transformations for reaching. Nature 416:632-636

Carnahan H, McFadyen BJ (1996) Visuomotor control when reaching toward and grasping moving targets. Acta Psychol (Amst) 92:17-32

Churchland AK, Lisberger SG (2002) Gain control in human smooth-pursuit eye movements. J Neurophysiol 87:29362945

Churchland MM, Chou IH, Lisberger SG (2003) Evidence for object permanence in the smooth-pursuit eye movements of monkeys. J Neurophysiol 90:2205-2218

de Lussanet MHE, Smeets JBJ, Brenner E (2001) The effect of expectations on hitting moving targets: influence of the preceding target's speed. Exp Brain Res 137:246-248 
de Lussanet MHE, Smeets JBJ, Brenner E (2002) The relation between task history and movement strategy. Behav Brain Res 129:51-59

de Lussanet MHE, Smeets JBJ, Brenner E (2004) The quantitative use of velocity information in fast interception. Exp Brain Res 157:181-196

Dessing JC, Bullock D, Peper CE, Beek PJ (2002) Prospective control of manual interceptive actions: comparative simulations of extant and new model constructs. Neural Netw 15:163-179

Dessing JC, Peper CE, Beek PJ (2004) A comparison of real catching with catching using stereoscopic visual displays. Ecol Psychol 16:1-21

Dessing JC, Peper CE, Bullock D, Beek PJ (2005) How position, velocity, and temporal information combine in the prospective control of catching: data and model. J Cogn Neurosci 17: 668-686

Eggert T, Rivas F, Straube A (2005) Predictive strategies in interception tasks: difference between eye and hand movements. Exp Brain Res 160:433-449

Engel KC, Soechting JF (2003) Interactions between ocular motor and manual responses during two-dimensional tracking. Prog Brain Res 142:141-153

Fayt V, Bootsma RJ, Marteniuk RG, MacKenzie CL, Laurent M (1997) The effects of task constraints on the organization of interceptive movements. J Sports Sci 15:581-586

Fitch H, Turvey MT (1978) On the control of activity: some remarks from an ecological point of view. In: Landers DH, Christina RW (eds) Psychology of motor behavior and sport. Human Kinetics, Champaign, pp 2-35

Flash T, Hogan N (1985) The coordination of arm movements: an experimentally confirmed mathematical model. J Neurosci 5:1688-1703

Gray R (2002) "Markov at the bat": a model of cognitive processing in baseball batters. Psychol Sci 13:542-547

Gribble PL, Ostry DJ (1998) Independent coactivation of shoulder and elbow muscles. Exp Brain Res 123:355-360

Jacobs DM, Michaels CF (2006) Lateral interception I: operative variables, attunement, and calibration. J Exp Psychol Hum Percept Perform 32:343-458

Ilg UJ, Schumann S (2007) Primate area MST-1 is involved in the generation of goal-directed eye and hand movements. J Neurophysiol 97:761-771

Indovina I, Maffei V, Bosco G, Zago M, Macaluso E, Lacquaniti F (2005) Representation of visual gravitational motion in the human vestibular cortex. Science 308:416-419

Kistemaker DA, van Soest AJ, Bobbert MF (2006) Is equilibrium point control feasible for fast goal-directed single-joint movements? J Neurophysiol 95:2898-2912

Krauzlis RJ, Lisberger SG (1994) A model of visually-guided smooth pursuit eye movements based on behavioral observations. J Comput Neurosci 1:265-283

Krauzlis RJ, Adler SA (2001) Effects of directional expectations on motion perception and pursuit eye movements. Vis Neurosci 18:365-376

Kruse W, Dannenberg S, Kleiser R, Hoffmann KP (2002) Temporal relation of population activity in visual areas MT/MST and in primary motor cortex during visually guided tracking movements. Cereb Cortex 12:466-476

Lacquaniti F, Maioli C (1987) Anticipatory and reflex coactivation of antagonist muscles in catching. Brain Res 406:373-378

Lacquaniti F, Maioli C (1989) Adaptation to suppression of visual information during catching. J Neurosci 9:149-159

Lazzari S, Vercher JL, Buizza A (1997) Manuo-ocular coordination in target tracking. I. A model simulating human performance. Biol Cybern 77:257-266
Lee DN, Young DS, Reddish PE, Lough S, Clayton TMH (1983) Visual timing in hitting an accelerating ball. Q J Exp Psychol A 35:333-346

Lee D, Port NL, Kruse W, Georgopoulos AP (2001) Neuronal clusters in the primate motor cortex during interception of moving targets. J Cogn Neurosci 13:319-331

Mazyn LI, Savelsbergh GJP, Montagne G, Lenoir M (2007) Planning and on-line control of catching as a function of perceptual-motor constraints. Acta Psychol (Amst) 126:59-78

McIntyre J, Zago M, Berthoz A, Lacquaniti F (2001) Does the brain model Newton's laws? Nat Neurosci 4:693-694

McLeod P (1987) Visual reaction time and high-speed ball games. Perception 16:45-59

Merchant H, Battaglia-Mayer A, Georgopoulos AP (2004) Neural responses during interception of real and apparent circularly moving stimuli in motor cortex and area 7a. Cereb Cortex $14: 314-331$

Montagne G, Laurent M, Durey A, Bootsma RJ (1999) Movement reversals in ball catching. Exp Brain Res 129:87-92

Mrotek LA, Soechting JF (2007a) Predicting curvilinear target motion through an occlusion. Exp Brain Res 178:99-114

Mrotek LA, Soechting JF (2007b) Target interception: hand-eye coordination and strategies. J Neurosci 27:7297-7309

Nuding U, Ono S, Mustari MJ, Büttner U, Glasauer S (2008) A theory of the dual pathways for smooth pursuit based on dynamic gain control. J Neurophysiol 99:2798-2808

Oldfield RC (1971) The assessment and analysis of handedness: the Edinburgh inventory. Neuropsychologia 9:97-113

Peper CE, Bootsma RJ, Mestre DR, Bakker FC (1994) Catching balls: how to get the hand to the right place at the right time. J Exp Psychol Hum Percept Perform 20:591-612

Port NL, Kruse W, Lee D, Georgopoulos AP (2001) Motor cortical activity during interception of moving targets. J Cogn Neurosci 13:306-318

Robinson DA (1965) The mechanics of human smooth pursuit eye movement. J Physiol 180:569-591

Saunders JA, Knill DC (2005) Humans use continuous visual feedback from the hand to control both the direction and distance of pointing movements. Exp Brain Res 162:458-473

Savelsbergh GJP, Whiting HTA, Bootsma RJ (1991) Grasping tau. J Exp Psychol Hum Percept Perform 17:315-322

Schenk T, Ellison A, Rice N, Milner AD (2005) The role of V5/MT+ in the control of catching movements: an rTMS study. Neuropsychologia 43:189-198

Smeets JBJ, Brenner E (1995) Perception and action are based on the same visual information: distinction between position and velocity. J Exp Psychol Hum Percept Perform 21:19-31

Soechting JF, Engel KC, Flanders M (2001) The Duncker illusion in eye-hand coordination. J Neurophysiol 85:843-854

Song JH, Nakayama K (2007) Automatic adjustment of visuomotor readiness. $\mathrm{J}$ Vis 7:2.1-9

Stocker AA, Simoncelli EP (2006) Noise characteristics and prior expectations in human visual speed perception. Nat Neurosci 9:578-585

Tabata H, Miura K, Kawano K (2008) Trial-by-trial updating of the gain in preparation for smooth pursuit eye movement based on past experience in humans. J Neurophysiol 99:747-758

Tanaka M, Lisberger SG (2001) Regulation of the gain of visually guided smooth-pursuit eye movements by frontal cortex. Nature 409:191-194

Teixeira LA, Chua R, Nagelkerke P, Franks IM (2006) Use of visual information in the correction of interceptive actions. Exp Brain Res 175:758-763

Tresilian JR (2005) Hitting a moving target: perception and action in the timing of rapid interceptions. Percept Psychophys 67: 129-149 
Tyldesley DA, Whiting HTA (1975) Operational timing. J Hum Mov Stud 1:172-177

Van Donkelaar P, Lee RG, Gellman RS (1992) Control strategies in directing the hand to moving targets. Exp Brain Res 91: 151-161

Werkhoven P, Snippe HP, Toet A (1992) Visual processing of optic acceleration. Vision Res 32:2313-2329

Whiting HTA, Sharp RH (1974) Visual occlusion factors in a discrete ball-catching task. J Motor Behav 6:11-16

Whiting HTA, Gill EB, Stephenson JM (1970) Critical time intervals for taking in flight information in a ball catching task. Ergonomics 13:265-272

Whitney D, Goodale MA (2005) Visual motion due to eye movements helps guide the hand. Exp Brain Res 162:394-400
Xiao Q, Barborica A, Ferrera VP (2007) Modulation of visual responses in macaque frontal eye field during covert tracking of invisible targets. Cereb Cortex 17:918-928

Zago M, Bosco G, Maffei V, Iosa M, Ivaneko YP, Lacquaniti F (2004) Internal models of target motion: expected dynamics overrides measured kinematics in timing manual interceptions. $\mathbf{J}$ Neurophysiol 91:1620-1634

Zago M, Bosco G, Maffei V, Iosa M, Ivaneko YP, Lacquaniti F (2005) Fast adaptation of the internal model of gravity for manual interceptions: evidence for event-dependent learning. J Neurophysiol 93:1055-1068

Zago M, McIntyre J, Senot P, Lacquaniti F (2008) Internal models and prediction of visual gravitational motion. Vis Res 48: $1532-1538$ 